\title{
A Case Study of Complete Streets Application in a Small Town
}

\author{
Diane M. Calloway, Ardeshir Faghri \\ Department of Civil and Environmental Engineering, University of Delaware, Newark, DE, USA \\ Email: faghri@udel.edu
}

How to cite this paper: Calloway, D. M., \& Faghri, A. (2020). A Case Study of Complete Streets Application in a Small Town. Current Urban Studies, 8, 545-562. https://doi.org/10.4236/cus.2020.84030

Received: October 12, 2020

Accepted: December 4, 2020

Published: December 7, 2020

Copyright (C 2020 by author(s) and Scientific Research Publishing Inc. This work is licensed under the Creative Commons Attribution International License (CC BY 4.0).

http://creativecommons.org/licenses/by/4.0/

\begin{abstract}
As research and evidence regarding the benefits of complete streets are growing, more and more communities are undertaking complete streets initiatives to increase transportation equity for their residents. This is especially vital for small towns, which often have the least opportunity for alternate transportation modes. The present article details a complete streets implementation procedure specific to the Town of Millsboro, Delaware, U.S.A. In this article, the current Millsboro Comprehensive plan is reviewed, followed by steps for planning, communication, and creation regarding various complete streets methods. The information presented in this document, along with the resources referenced, should be used as a guide for turning existing roadways in Millsboro into complete streets. The various suggestions and recommendations offer ideas to increase the opportunity for active transportation modes such as walking and biking, and if implemented, can create significant improvements in safety, health, and the economy of Millsboro, thereby enabling it to grow as a town.
\end{abstract}

\section{Keywords}

Complete Streets, Millsboro, Delaware, Implementation Process

\section{Introduction}

Complete streets are roadways which provide equal access to all modes of transportation without giving preference to a single mode. As previous decades have seen our transportation environment give more and more preference to automobiles, other modes, particularly walking and bicycling, have been marginalized. However, the complete streets movement is attempting to reverse that trend, and there is growing research regarding the many benefits of complete streets all over the world. In particular, complete streets are needed most in small 
towns or rural settings, where a lack of adequate transportation infrastructure means that these residents often have the least opportunities for active transportation modes. The present article focuses on the implementation of complete streets specifically for the Town of Millsboro, a relatively small town with a population of around 4600, located in Sussex County, Delaware, U.S.A.

\section{Millsboro, DE}

Municipalities in Delaware are generally separated by at least 7 miles, which was historically the distance easily travelled by horse. The geographical layout of southern Delaware varies greatly to that of the urbanized upstate area north of the Chesapeake and Delaware Canal, which runs horizontally across the state just under Delaware City. New Castle County is the northernmost county and has become very populated. Travelling from Wilmington to Newark, there is very little open area which hasn't been developed and become urbanized. The case is completely different in Sussex County which is the southernmost county in the state. There are great expanses of farm fields and woodlands that separate all of the municipalities, making it a far more rural environment. Figure 1, a map of the state of Delaware, shows the three counties and their towns/cities, which shows this disparity between the northern part of New Castle County and Sussex County. The eastern side of Sussex County is bordered by the Atlantic Ocean and is well populated and developed, as it must accommodate many beach goers in the summer months. The western side is far more rural and far less populated. The town of Millsboro is nestled right in the middle of the county, slightly towards the southeast, making it a vital transportation link for residents from the west to get to the beach.

From an economic standpoint, Sussex County has considerably low property taxes and good healthcare systems. This combination of qualities has led to a retirement rush to Sussex County in the post 9/11 era. This influx of retirees has increased the median age substantially. According to the most recent United States Census Data, Sussex County population in 1990 was 113,229 and experienced a 74.77 percent increase to 197,890 in 2010. Since then, it has experienced an annual average increase of about 2 percent. In 1990, the Senior population in the county was $23.3 \%$ of the overall population, $28.6 \%$ in 2000 and $30.9 \%$ in 2020 . Due to the increased elderly population, there has been an increase in the number of drugstores, medical offices and medical supply stores. This retirement draw is only exacerbated by the relatively mild 4 season climate that Millsboro enjoys and its small-town charm.

\section{Implementing Complete Streets in Millsboro}

Millsboro's small-town charm is an important factor that attracts new residents. As previously mentioned, the proximity to clean and prestigious Atlantic Ocean beaches, relatively mild four-season climate, safe and secure residential and commercial areas are all important factors for attracting new population. Like an 


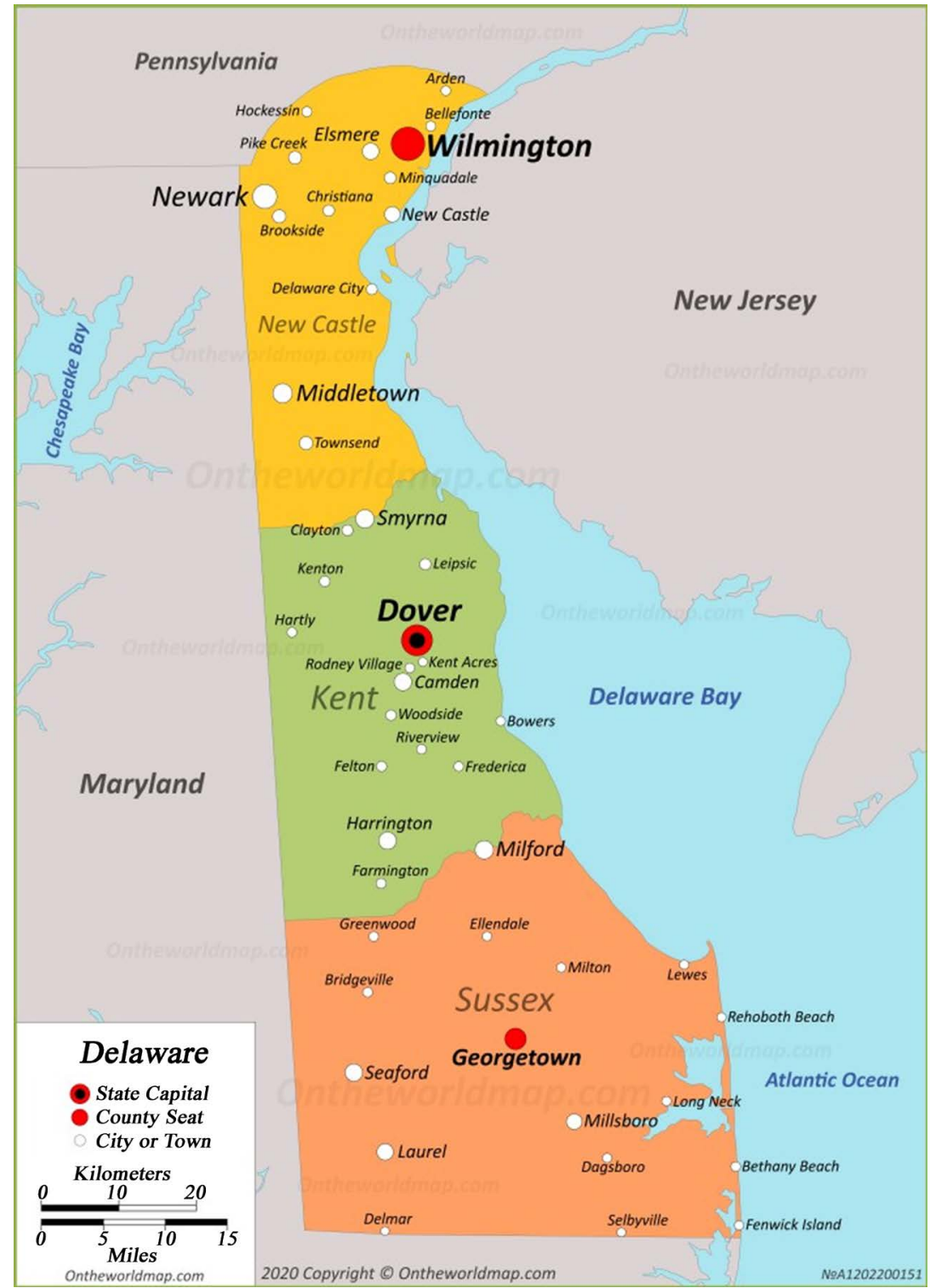

Figure 1. County map of Delaware (On the World Map, n.d.)

open picture book, the draw of an inviting downtown brings commercial growth and desire to live in that picturesque landscape. The qualities and benefits that complete streets provide to any small town will bring even more charm, beauty and economic vitality to the Millsboro area. In order to successfully implement complete streets in Millsboro, the design must complement the existing environment. The following detailed step-by-step method should be adhered in order to create effective complete streets in this town.

\subsection{Step 1: Review Current Comprehensive Plan}

In studying the Town of Millsboro, the Comprehensive Plan serves as the road map for the town's growth. The most current adopted Comprehensive Plan is the 2009 Update to the 2004 Town of Millsboro Comprehensive Plan. The Town 
has also recently developed a 2020 Comprehensive Plan (Draft Plan) which considers its current situation and plans for growth and improvement. The town has almost doubled in size since the 2004 Comprehensive plan was written. According to the most recent United States Census Data, in 2004 the population of Millsboro was 2571 and increased to 4446 in 2018.

The Draft 2020 Comprehensive Plan focuses on two main areas of growth for the town. These two focus areas are planning for future expansion and improving downtown Millsboro (Town of Millsboro, 2020). According to the Plan:

"The future of the Town will be shaped by the quality of transportation facilities and interconnection between land use decisions and the provision of appropriate transportation investments... As Millsboro continues to grow it anticipates that residents will mainly meet their transportation needs through motorized vehicles, but the Town will encourage walking and bicycling for local trips through an increased focus on providing and maintaining safe pedestrian and cycling infrastructure" (Town of Millsboro, 2020).

The Plan observes that "Rapid growth has caused major traffic congestion throughout the County, and Millsboro has seen an increase in traffic delays along Route 24 and US 113", a major concern regarding its current transportation network (Town of Millsboro, 2020). It also includes public feedback and the results of information collected, which found that the lack of walkability is a big issue connected with the traffic related transportation problems. Residents suggested that more sidewalks in the downtown area would create better connectivity and make walking safer (Town of Millsboro, 2020).

Furthermore, the plan reports that for the Town's open house held in October 2018, "The participants all noted how effective the pedestrian mobility and recreational facilities have been in creating the feeling of a safe community in particular parts of town and that they would like to see this integrated into future development... there are key areas where recreation would thrive if infrastructure was improved" (Town of Millsboro, 2020). Additionally, the Plan includes data from the State of Delaware Statewide Comprehensive Outdoor Recreation Plan (SCORP) which is updated every 10 years, most recently in 2018. Millsboro falls in region 5 of the SCORP, and the 2018 data reports that respondents in the Millsboro area have the following participation rates in active recreation, as shown in Table 1.

Table 1. Outdoor recreation data (Town of Millsboro, 2020).

\begin{tabular}{cc}
\hline Activity & Participation \\
\hline Walking or Jogging & $81 \%$ \\
Beach Swimming & $79 \%$ \\
Fishing & $66 \%$ \\
Visiting Historic Sites & $65 \%$ \\
Bicycling & $64 \%$ \\
\hline
\end{tabular}


These data show that there is an interest in outdoor recreation and if trails and multi-modal paths are created to link these areas of recreation, the Town residents and guests will use them.

The second overall strategy that the town identified as part of their draft Plan for the Open Space and Recreation section was to (Town of Millsboro, 2020):

Expand recreational facilities making greater use of existing open space, waterways amenities and facilities.

1) Expand recreational use of Millsboro Pond. Evaluate potential public access points for non-motorized recreational boating opportunities and water trails.

2) Explore options to develop partnerships and agreements with the Millsboro Library to utilize the lands behind the library as parkland with outdoor reading pavilions, non-motorized recreational boat launches and/or observation piers, and the U.S. Postal Service to place amenities, such as a fountain, clock, and/or park benches, on the land adjacent to the current Post Office.

3) Improve Town Owned open space west of US 113 with low impact activities, such as nature and exercise trails.

These recreational improvements, if implemented, will provide destination nodes that need to be linked to origins from the residents of Millsboro. Overall, the Town of Millsboro states that in the near future, they intend to encourage sustainability and promote fully connected multimodal networks to provide safe and efficient mobility alternatives (Town of Millsboro, 2020).

Not only does the Town recommend improvements relating to incorporating complete streets, but they also include community service-oriented improvements which will make these multi-modal investments more appealing and safer. The Plan calls for “...installing new or updated lighting on streetscapes, increase the amount of wayfinding and signage available to the public, and making the downtown a more pedestrian friendly area" (Town of Millsboro, 2020). This improved lighting will help the Town support an initiative to perform Crime Prevention through Environmental Design (CPTED).

The Plan also identifies strategic planning documents which the town currently does not have to help with decision making. The Town currently does not have a comprehensive stormwater management plan or a transportation plan. According to the Comprehensive Plan, “...the stormwater infrastructure is fragmented, flooding issues will arise with the requirement of new sidewalks, and pollutants may be more prone to enter both surface waters and the underground aquifers" (Town of Millsboro, 2020).

Although the Town of Millsboro does not have a master transportation plan, they have drafted and adopted a Downtown Improvement Plan. The Downtown Improvement Plan (DIP) was written in consultation with AECOM and officially adopted and endorsed in February 2019. The DIP focuses on the downtown historic portion of the Town, though many of the recommendations can be expanded to the Town in its entirety. The Downtown Improvement area of study (Figure 2) is bounded on the north by the Indian River. On the east, it is bound 


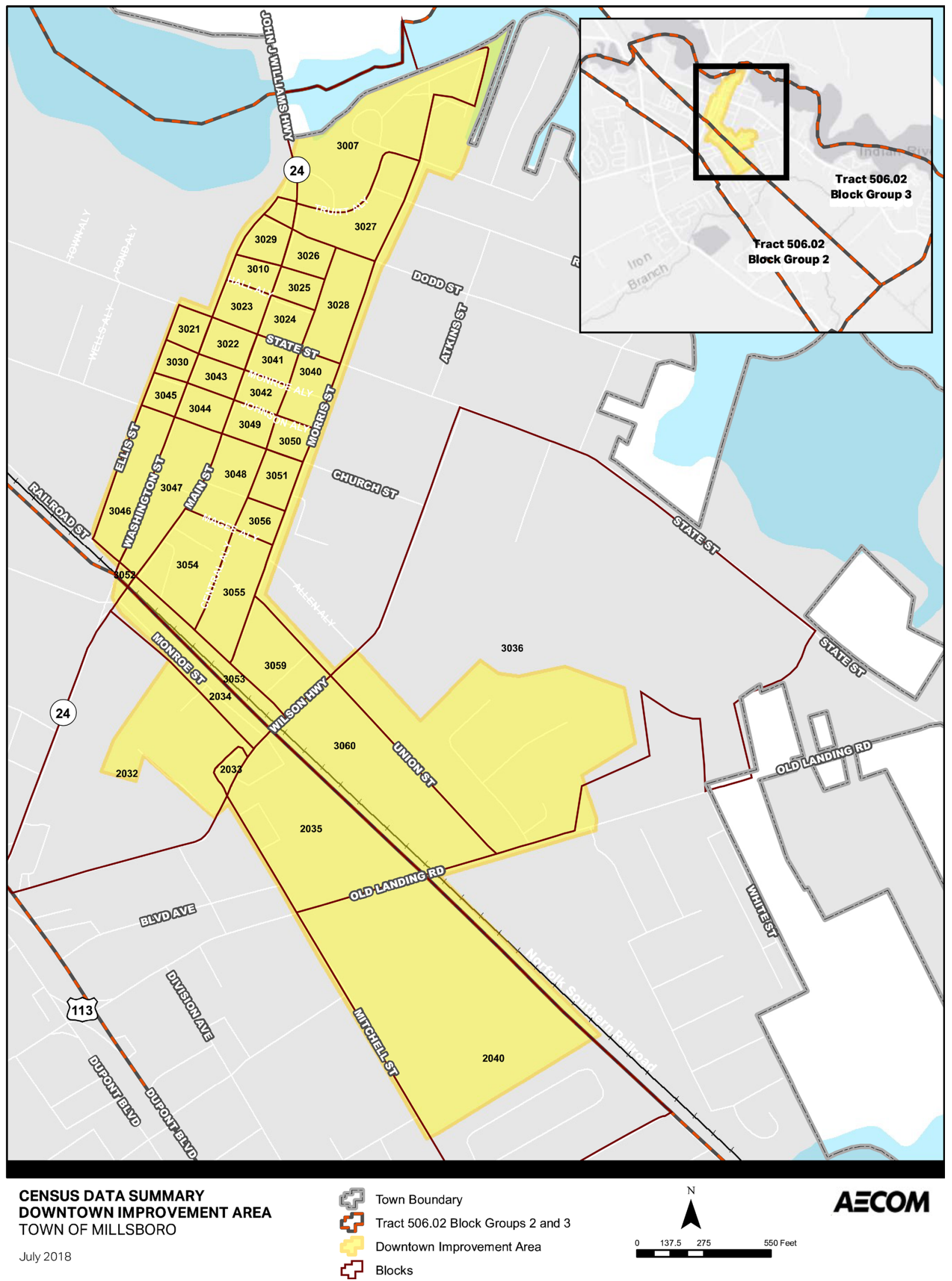

Figure 2. Town of Millsboro downtown improvement plan area. 
by a meandering line starting at the intersection of Morris Street and the Indian River and going coincident with Morris Street south to Union Street, then heading east to Wilson Hwy. At the intersection with Wilson Hwy, the boundary expands to parcels on the north of Union Street through the intersection of Old Landing Rd, then by and with the Norfolk Southern Railroad rights-of-way to the limits of the Hub Court-Nash Circle subdivision, then coincident with said Hub Court property southwest to Mitchell Street. Then, it turns northwest along the rights-of-way of Mitchell Street to the intersection with Wilson Hwy and expands to properties on the southwest of Monroe Street to the intersection of Monroe Street and DE. Rt. 24. Thence, it goes along the western right-of-way line of Washington Street then west to Ellis Street. Finally, it traces along the western right-of-way of Ellis Street north to State Street and then east to Washington Street and travelling coincident with Washington Street to DE. Rt. 24 to the junction with the Indian River.

The DIP identifies recommendations and classifies them as either high, medium or low priority. These priorities were sorted based on 4 criteria:

1) The level of importance towards achieving downtown development goals;

2) Are intrinsically linked with the Comprehensive Plan Update process, which is currently underway;

3) Prevent potential development or redevelopment; and

4) Are key strategies and programs that have the ability to leverage outside funding.

Several transportations related recommendations were noted based on the priority guidance provided. The DIP high priority recommendations for the downtown district of Millsboro were to amend zoning code for less-strict parking requirements, invest in streetscape beautification, and identify priority projects for transportation alternatives funding. The medium priority recommendations for the downtown district were to explore opportunities to increase downtown parking options, identify and prioritize sidewalk gaps for infill, develop a town pedestrian/bicycling master plan, prepare a way finding plan, explore recreational opportunities (especially along the waterfront), and explore opportunities to enhance public transportation offerings downtown. The low priority transportation recommendations identified are to consider a sidewalk loan program, identify and implement appropriate traffic calming measures, and improve green/open space and parks downtown. These recommendations can be greatly improved and tied together if bundled with a complete streets master plan.

\subsection{Step 2: Communicate with Stakeholders}

In several conversations with Town officials, there is currently a focus on economic development by the Town Manger. He envisions Millsboro as a thriving town and a destination within Sussex County. He has branded the town as "The 
TRULY Probusiness, Profamily Town. Ask Anyone!” (Town of Millsboro, n.d.). The Town of Millsboro is proud that they are fastest growing town in the fastest growing county in the State of Delaware. He frequently points out that Millsboro is second only to Middletown in the number of building permits filed in the state. So how can complete streets fit into the current vision of the town? That is where the profamily part of the slogan comes in. In order for parents to feel comfortable walking, biking, or strolling down the street with their families, they have to be safe and complete.

In speaking with several residents of the town, most of whom live in the Plantation Lakes subdivision, they all want amenities for their children. They want to be able to get from one side of town to the other in less than 30 minutes. They want to be able to ride their bicycles to get a gallon of milk or go out to eat and not sit stuck in traffic for such a long time. By providing complete streets, they can get many of the items the wish for.

\subsubsection{Assess the Location/Destination Hubs \& Pathways}

There are commercial buildings scattered from the northwest to the southeast along U.S. Rt. 113 and from the northeast down to the southwest along DE. Rt. 24. These two main corridors separate the town into 4 quadrants of primarily residential areas. The two quadrants on the north and east are the older sections of town and the two on the southwest of U.S. Rt. 113 are the newly annexed portions of town which are rapidly growing. Plantation Lakes on the west is a partially built subdivision which will double the population of the town once fully constructed. This high-density residential area is a main origin location as are the residential areas of the north, east and southern quadrants. The destination hubs are primarily the southeastern portion of U.S. Rt. 113 and the northeastern portion of DE. Rt. 24. These retail areas are the new commercial centers and historic downtown area respectively.

\subsubsection{Determine the Ownership and/or Maintenance Responsibility of the Roadway}

The current ownership and maintenance responsibilities of the roadways within the limits of the Town of Millsboro are shown in Figure 3. As the figure shows, the maintenance falls between either the State of Delaware (red and gold colored roadways), Town of Millsboro (blue colored roadways) or privately owned and maintained (uncolored). The main commercial roadways fall within State maintenance and the residential areas are either Town of Millsboro maintained or privately owned and maintained. Though the streets within the Town may be owned or maintained by the State, each municipality within the State of Delaware has (a) maintenance agreement (s) with DelDOT on what will and won't be maintained and from where to where along the rights-of-way. For example, the State might only maintain from face-of-curb to face-of-curb or the entire right-of-way.

In researching the agreements provided by the Town of Millsboro, there is 


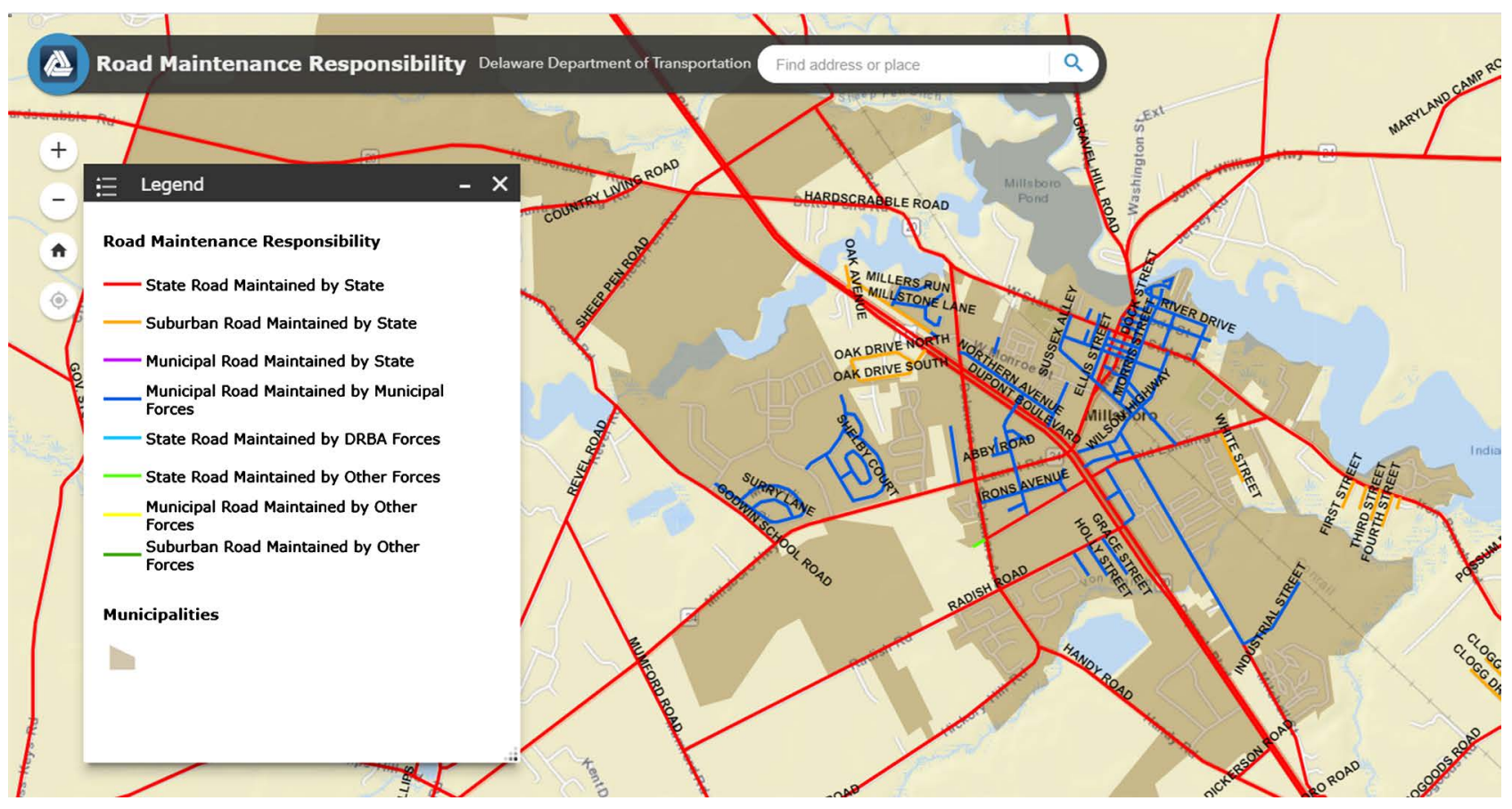

Figure 3. Town of Millsboro road maintenance responsibility.

consistency in that DelDOT maintains the roadway and everything within the rights-of-way, but outside of the roadway is the maintenance of the Town. Within the Town of Millsboro, the maintenance responsibilities are not uniform and there are multiple agreements between the Town and DelDOT for maintenance of each "state maintained" roadway. For example, Laurel Road (State Route 24) is referenced in several of these agreements. An agreement made on September 9, 1999 in relation to Contract 97-109-03 references work proposed on U.S. Route 113 and S.R. 24. This contract states that after construction is completed, the state (DelDOT) will maintain perpetually the roadway between face of curb and face of curb. Then eight years later, another letter agreement referencing a smaller portion of U.S. Route 113 and S.R. 24 regarding Contract 27-063-01 dated December 5, 2006 states that after construction, the State will assume responsibility for the maintenance from edge of pavement to edge of pavement. Then, in 2010, DelDOT proposed improvements for the intersection of Rt. 113 and Second St./Radish Rd (DelDOT, 2010). In order to determine the actual rights and maintenance responsibilities for all the "state maintained" roadways, it would require a full title search and FOIA request to both agencies. For the purposes of this article, the Town provided all documents they had on file and the DelDOT Agreement online repository was accessed. In order to properly ascertain rights and legal maintenance responsibilities, further research would be required. If a full-scale planning georeferenced map were to be created, this information would be critical for planning the proposed projects.

Regardless of whether DelDOT maintains from face-of-curb to face-of-curb or edge-of-pavement to edge-of-pavement, the one consistent message in all the 
agreements was that DelDOT was accepting maintenance of all vehicular portions of the roadway and turning all other stormwater maintenance to the Town in each agreement. One agreement dated May 28, 1956 specifically calls out that the Town is responsible for not only all storm water sewer infrastructure, but also the present and future sidewalks of Washington Street, sewer lines and private utilities. Due to the numerous changes and piecemealed nature of these agreements, it is strongly encouraged that the Town determines the ownership and maintenance responsibilities of all roadways within town limits.

\subsubsection{Assess the Width of the Existing Rights-of-Way}

Unfortunately, neither the Town of Millsboro, nor the State of Delaware keep inventoried data on the rights-of-way along each individual roadway. However, the Town does have the original plat of the roadway design in a framed plat hanging in their town museum. For the most part, the official widths of the rights-of-way within the Town of Millsboro would have to be determined by complex deed research on each individual parcel within the town. Based on the width of rights-of-way found for different streets, officials can determine how to best use that space. The context and environment of each street must also be taken into account, but the width can be used to assess whether the best complete street implementation is a sidewalk, wider shoulder, or a bike lane. Conversely, for a particularly narrow space, perhaps traffic calming measures can be used to make the street more complete.

\subsubsection{Determine Funding and Partnerships Available}

There are numerous funding options and partnerships available to the Town of Millsboro for implementing complete streets. Having attended a meeting between the Town of Millsboro and DelDOT, there are funding options to help the Town fill in the gaps of their infrastructure. These funds would be in the form of matching grants to the investment the Town is willing to contribute. The Town is currently working on some public-private initiatives for street cameras to improve safety and security and to improve business signing along Main Street.

Other potential partnerships could be with nationwide or international advocacy groups. The Town should research possible collaboration with bicycle and pedestrian groups such as Bike Delaware, whose goal is to make “...cycling and walking safe, convenient, and fun in Delaware" (Bike Delaware, n.d.). In addition, the Town should build relationships with regional planning authorities for grant funding and technical assistance (Azeez, 2017). Millsboro is not currently a member of a metropolitan planning organization (MPO) and is geographically outside of the limits of both the Dover/Kent County MPO and the Salisbury-Wicomico MPO.

\subsubsection{Perform Surveys \& Town Hall Meetings}

Should the Town of Millsboro decide to promote complete streets within the jurisdiction, they would need to perform this step as part of the process. The Town 
has gathered public feedback as part of the comprehensive plan update and downtown development plan. This includes the public interest in a more connected sidewalk network in the downtown area, which was referenced before while discussing the Comprehensive Plan. Such feedback as noted was supportive of complete streets initiatives. Additionally, feedbacks for U.S. Route 113 improvements were provided by many stakeholders in DelDOT's Environmental Impact Statement on the U.S. Route 113 bypass in the Millsboro-South area (DelDOT, 2016). This was mostly intended to deal with concerns with heavy vehicular through traffic, as well as environmental and safety concerns, and was not focused on implementing complete streets. However, feedback like this to improve Rt. 113 could free up traffic within streets in Millsboro, which could allow opportunities to make them more accessible for different modes.

\subsection{Step 3: Implement Appropriate Complete Streets Strategies}

Using this document and guidance provided by FHWA, DelDOT, UD's IPA and their Comprehensive Plan, the Town should identify complete streets strategies to implement. These strategies should be identified to be implemented in the short-term, near-term, and long term so to phase the improvements into more manageable and economically reasonable scale.

\subsubsection{Prioritize ALL Users}

Currently within the Town of Millsboro, there are facilities for vehicles and partial accommodations for pedestrians. The sidewalk network is broken, fragmented and not meeting standards set by the Americans with Disabilities Act (ADA, 1990). There are residents in Town limits with mobility impairments who are unable to safely traverse the area on the roadway adjacent to their homes. It would be in the Town's best interest to link ALL residential areas west of Rt. 113 to the commercial areas to the south and east.

\subsubsection{Designate No-Vehicle Plaza at Downtown Location}

The Town should remove parking on Washington Street and institute two-way vehicular traffic on that roadway. That would provide an east-west connection for vehicles intending to pass through town until the DelDOT North Millsboro Bypass project is completed. The Town should then restrict any vehicular traffic on Main Street between Church Street and Dodd Street (Cross traffic would be permitted on State Street). This would serve as the Town's main shopping and pedestrian friendly plaza.

\subsubsection{Invest in Signing and Striping}

Signing and striping improvements change the geometry without having to perform construction. These improvements can be done with a temporary lane closure are much more cost effective than designing and building separate road infrastructure. Additionally, signage and striping can be used to test whether more pedestrians or bicyclists are willing to use certain roads before implementing more 
long-term or lasting infrastructure to accommodate those travel modes.

\subsubsection{Research Availability of Public Transport}

The Town should have a meeting with the Delaware Authority for Regional Transit (DART), which is managed by the Delaware Transit Corporation (DTC) as a branch of DelDOT, to discuss current transit opportunities, long range growth options, and opportunities to partner on projects to expand transit options to the residents of the Town of Millsboro. One possible option is to create a beach shuttle from Millsboro to the Lewes Park and Ride during the summer months. Utilization of this option would reduce not only east-west traffic through town, but also overall traffic on DE. Rt. 24 John J. Williams Highway. Another consideration would be implementing a water vessel service from Millsboro to Dewey Beach. Because of its unique location along the headwaters of the inland bays, this option may be a point of consideration with another private company as a partner. Another option would be to improve connections with nearby residential municipalities with limited retail options such as the communities of Gumboro, Laurel, and Dagsboro. If transit routes were provided that were economical, timely, and dependable, the Millsboro businesses could gain additional clientele.

\subsubsection{Identify Traffic Calming Measures That Would Function in All Speed Zones}

Several residential streets which already have reports of frequent speeding would be designed to calm traffic and slow the speed of vehicles. By implementing traffic calming measures, not only will vehicles slow down, but the improvements will also reduce any cut-through traffic. Roadways identified for these measures after interviewing the Chief of Police would be West State Street near the Little League fields, East State Street in the vicinity of the Sussex Central Middle School, and Union Street.

Streets with a known history of aggressive driving and excessive speed should also be updated with traffic calming measures. The streets most in need of this treatment would be SR 24 from west of US Rt. 113 west to the town boundary and Mitchell Street, which runs north-south from Main Street south to the southern boundary of town. A potential design for SR 24 would be a speed table at the intersections with Wharton Street and a full roundabout at the intersection with Delaware Avenue, followed by another at the entrance to Plantation Lakes. These roundabouts, while not officially traffic calming measures, would be beneficial as they reduce the number of traffic collision points and cause traffic to be laterally diverted to enter the roundabout. They also could serve as a landscaped welcome feature similar to Maryland SR17 Burkittsville Road in Knoxville, Maryland, which is shown in Figure 4. Mitchell Street would benefit from a variety of speed management tools spaced approximately every 300 feet. The design could include a speed treatment train of connected measures. The potential design could include the following layout from north to south along 


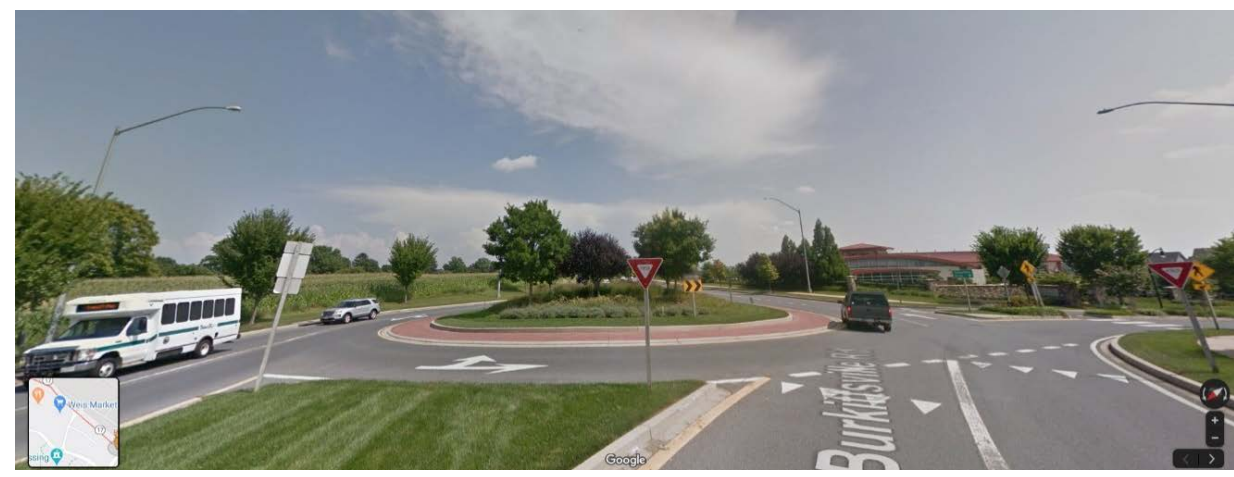

Figure 4. Google street view of Burkittsville road roundabout.

Mitchell Street:

1) Old Landing Road-roundabout;

2) $1^{\text {st }}$ Street-speed table;

3) Tristan Lane-mini roundabout;

4) Nash Circle-speed table;

5) Kyle Circle-mini roundabout;

6) Marie Drive-roundabout;

7) Scott Drive-mini roundabout;

8) Arwill Lane-speed table.

\subsubsection{Improve All Areas for ADA Accommodations}

All new DelDOT and Town projects are required to comply with ADA regulations. In order to provide transportation equity to all modes, a thorough and detailed assessment of current infrastructure needs to be completed. By geographically identifying current amenities, it would be easy to identify project areas that could address the gaps currently in existence. These gaps would form the short-term project list. Then once these gaps were retrofitted, the focus would shift to implementing new ADA compliant paths to link origins and destinations around town which would become the near and long-term list of projects.

The Town has made some improvements along Main Street, but from site visits to the area after a recent rainfall, there is room for improvement. An example of a poorly designed curb entrance collecting rainwater is shown in Figure 5. Also, Main Street is currently in design and near construction for a sidewalk improvement and rehabilitation. An example of a non-ADA compliant sidewalk ramp on Main Street is depicted in Figure 6. The current curb ramps will be updated within 12 months during the upcoming construction project.

\subsubsection{Classify Streets by Speed, Not Use}

Speed plays a critical role in the future safety of the residents of Millsboro. Federal Highway Administration data indicates that between 20 and 40 mph speeds, the fatality rate for a collision with a pedestrian decrease by $40 \%$ for every 10 mph decrease (FHWA, 2014). All residential streets within the Town should be classified as $25 \mathrm{mph}$. Should the $25 \mathrm{mph}$ speed still be considered too fast, traffic 


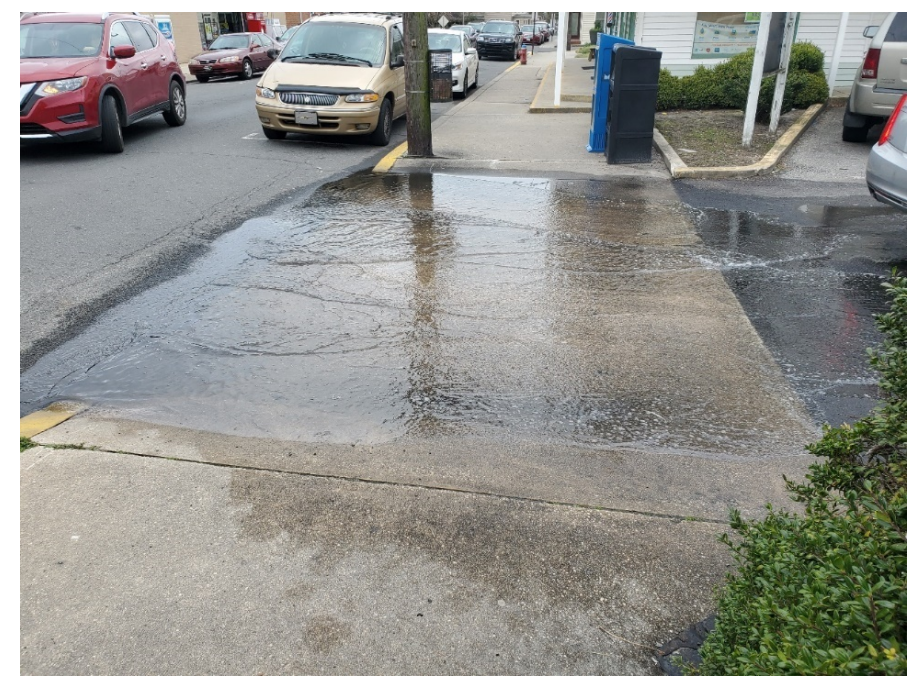

Figure 5. Standing water on sidewalk at curb entrance on main street (Calloway, 2020a).

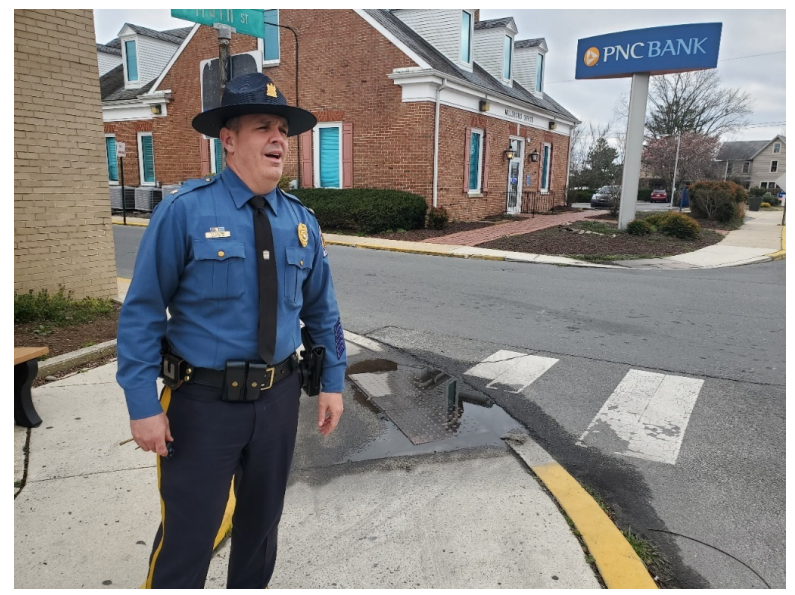

Figure 6. Town of Millsboro police chief standing in front of non-compliant curb ramp on main street (Calloway, 2020b).

calming measures can be implemented to further reduce those speeds. If any speed analysis or change were to be recommended, the enforcement of that speed will be critical to the success of the project. According to the Chief Calloway, the town does already own two stationary speed notification units. These units are posted on the west side of town limits on SR 24 and on West State Street near Little League fields. The Millsboro Police Department would be greatly interested in acquiring mobile speed notification units which could be placed in areas of known speeding and serve as a reminder to motorists that they are going above the speed limit. The Town has had recent success with this initiative for the two stationary units.

\subsubsection{Identify Ways to Innovate and Incentivize Local Business Owners to Provide Public-Private Partnerships}

Should the Town of Millsboro decide to promote complete streets within the jurisdiction, they would need to perform this step as part of the process. The local 
businesses and organizations along Main Street want to promote foot traffic to patronize their establishments. The Town should partner with the Millsboro Chamber of Commerce to create a plan for the completeness of Millsboro streets and therefore spark a partnership of resources to promote the projects.

\subsubsection{Identify Locations for Road Diets}

A road diet involves repurposing some vehicle lanes of a multi-lane road into area for active transportation (sidewalk, bike lane, shoulder). The Town of Millsboro does not currently have multi-lane roadways. The only 4-lane roadway is U.S. Route 113. From desktop reconnaissance, there is no immediate area for implementing a road diet other than the removal of a travel lane from Main Street to provide the pedestrian plaza.

One possible opportunity for slimming down a roadway would be reduce the number of lanes down to a single shared bidirectional lane. Two possible options would be to designate select residential streets to be yield roadways or advisory shoulders. Roadways that would be ideal candidates for this treatment would be Church Street, Dodd Street and River Drive.

\subsubsection{Invest in Biking Infrastructure and Encourage Biking Culture}

Millsboro should also actively participate in Delaware's statewide initiative to increase bicycle safety and accessibility to encourage more people to use bicycles as their mode of travel. Delaware is already one of the most bike-friendly states in the US, and were ranked $6^{\text {th }}$ out of the 50 states in this respect based on public data sources and the Bicycle Friendly State survey, which is answered by each state's DOT (League of American Bicyclists, 2019). The previous suggestion of road diets on certain streets is one of the high priority methods for converting vehicle lanes into bike lanes according to DelDOT's Statewide Bicycle Policy Plan (DelDOT, 2018). However, there are many other methods to provide bicycling opportunities, such as using traffic calming measures to increase safety, using bicycle signage on low-speed roads, providing wider shoulders for cycling, creating bicycle parking stations near destinations and amenities (especially downtown), and implementing trails between destinations. In concurrence with such infrastructure, education is important to encourage a culture of bicycling, and this can be achieved by providing information on the town website, organizing bicycling events, and creating safety programs or training courses.

\subsection{Step 4: Continue Active Communication with Public}

Should the Town of Millsboro decide to promote complete streets within the jurisdiction, they would need to perform this continually as part of the process. At every milestone of project delivery, the Town should provide updates and information using their variable message board located across from the Post Office and on their website. True transparency and managing expectations will lead the public to trust the Town administration and feel buy-in to the goals and direction of the implementation of complete streets. 


\subsection{Step 5: Review All Recommendations through the Lens of Safety}

Once the final plan has been drawn, the analysis should circle to safety. Does the plan improve access to all, while also promoting increased safety? To simply build a bike lane, but then have the bicycling accidents increase, would not be a project worth doing. All improvements to the transportation network must be actual improvements, not Band-Aids. Review of existing traffic patterns, accidents, and complaints should be evaluated before a shovel breaks ground. Even after the completion of projects, safety data should be collected to ensure that they are working as intended.

\section{Summary}

The purpose of complete streets is to focus on all users. In the Town of Millsboro, this will bring unity, connecting residential origins to destination nodes, especially in the downtown area. No matter whether it is to pick up some groceries or go to a hardware store, to go out and grab a bite to eat, or pick up mail, Millsboro residents should have the opportunity to use active transportation modes instead of being forced to use a car. By implementing alternative transportation options to provide complete streets to residents and guests, Millsboro can experience the benefits of better air quality, personal safety, physical fitness, happiness, and overall community connectivity.

This article provides a detailed step-by-step procedure for implementing complete streets specific to the Town of Millsboro. The town already has a Comprehensive Plan for improvements as discussed in this document, but there should be a keen focus to implement complete streets. Thus, the first step discussed was to examine all the transportation areas of the Draft 2020 Comprehensive Plan that must be addressed and can potentially make streets more complete. Then of course, before beginning implementations, planners must speak to stakeholders, such as residents and business owners, in order to understand their opinion and feedback regarding the improvements they wish to see and how they believe roadways can be changed to accommodate these different modes. This requires surveys, town hall meetings, and data collection. After that, implementations can be discussed, and several different methods for implementing complete streets in Millsboro have been identified and discussed in this document. Finally, in order to ensure the success of these implementations, officials must continue communication with the public who are affected by these changes, and they must continue to ensure that all implementations be examined for safety, as that must stay the top priority for any complete streets initiative.

Completing streets in any small town or rural community can start the process to be more welcoming, more accessible, and more diverse, and Millsboro is no exception. By going step-by-step through the implementing process for the Town of Millsboro, planners and local advocates can see a clear procedure to increase transportation equity within the Town. There isn't one single design or 
layout that will work for all streets in Millsboro, but this document provides a variety of ideas for planning, designing, and testing such improvements on different streets. Additionally, while this article is specific to the town of Millsboro in Sussex County, Delaware, U.S.A., a generalized procedure from the given plan can be implemented in any small town.

This article presents original research on how an existing comprehensive planning document can be coupled and integrated with the principles of complete streets planning and design specifically for small towns to provide the stakeholders and decision makers a road map on how to actually implement complete streets in a typical small town. But of course just like any other research articles, there were limitations that can be addressed in the future stages of this research project. Most notably, the interviews with the residents, stakeholders, and decision makers need to be conducted and documented. Only through a context-sensitive approach and participation by all parties involved one can definitely draw the plans and designs for a successful complete streets implementation in Millsboro or any other small town. Furthermore, more quantitative measures need to be taken and included in the research. This will include all the necessary infrastructure related surveys and measurements including the geometric, operational, environmental and health-related surveys and measurements.

\section{Conflicts of Interest}

The authors declare no conflicts of interest regarding the publication of this paper.

\section{References}

ADA (1990). Americans with Disabilities Act of 1990. Pub. L. No. 101-336, 104 Stat. 328.

Azeez, N. (2017). Implementing Complete Streets in Small Towns and Rural Communities. Smart Growth America.

https://smartgrowthamerica.org/implementing-complete-streets-small-towns-rural-co mmunities

Bike Delaware (n.d.). Homepage. https://www.bikede.org

Calloway, D. M. (2020a). Curb Entrance on Main Street [Photograph].

Calloway, D. M. (2020b). Police Chief Brian Calloway and Non ADA Compliant Curb Ramp [Photograph].

DelDOT (2010). HSIP Sussex County, US 113 Intersection Improvements. https://deldot.gov/information/projects/CompletedProjects/sussex_county_us113/pdf/ workshops/062110/location_three.pdf

DelDOT (2016). US 113 North/South Study Millsboro-South Area Supplemental Draft Environmental Impact Statement [Report]. https://deldot.gov/information/projects/us113/millsboro/pdfs/SDEIS/US113MillsboroSouthSDEIS-Appendices.pdf

DelDOT (2018). Blueprint for a Bicycle-Friendly Delaware: A Statewide Policy Plan [Report]. 
https://deldot.gov/Publications/plans/bikeandped/pdfs/DelDOTBikePlan043018FINAL .pdf

FHWA Federal Highway Administration (2014). Speed Concepts: Informational Guide. US DOT. https://safety.fhwa.dot.gov/speedmgt/ref_mats/fhwasa10001

Google Street View (n.d.). Street View of Burkittsville Road [Image]. https://www.google.com/maps/@39.3328379,-77.6339274,3a,75y,128.17h,103.15t/data= !3m6!1e1!3m4!1sAt08e9Om7eaFNbUvRx1TPA!2e0!7i13312!8i6656?hl=en

League of American Bicyclists (2019). 2019 Bicycle Friendly State Ranking. https://bikeleague.org/content/ranking

On the World Map (n.d.). Delaware Map [Image]. http://ontheworldmap.com/usa/state/delaware

Town of Millsboro (n.d.). Homepage. https://www.millsboro.org

Town of Millsboro, AECOM (2020). DRAFT 2020 Town of Millsboro Comprehensive Plan [Report].

https://www.millsboro.org/images/Millsboro\%202020\%20Draft\%20Comprehensive\%2 0Plan\%20040620.pdf 